\section{Predicting hearing outcomes before primary radiosurgery for vestibular schwannomas}

TO THE READERSHIP: Two errors appeared in the article by Johnson et al. (Johnson S, Kano H, Faramand A, et al: Predicting hearing outcomes before primary radiosurgery for vestibular schwannomas. J Neurosurg [epub ahead of print September 6, 2019; DOI: 10.3171/2019.5. JNS182765]).

In the lower part of Fig. 3, the heading "No. at Risk" was moved to the right. The corrected figure is shown here.

In Table 2, the percentages for the first line ("Entire series") were incorrect. The corrected table is shown here.

The article has been corrected online as of October 18, 2019.

Hideyuki Kano, MD, PhD University of Pittsburgh, Pittsburgh, PA
TABLE 2. Serviceable hearing (GR grade 1-2) preservation rates

\begin{tabular}{lccc}
\hline & $3-Y r$ HPR & 5 -Yr HPR & $10-Y r$ HPR \\
\hline Entire series & $78 \%$ & $69 \%$ & $52 \%$ \\
\hline Age $<45$ yrs & $89 \%$ & $86 \%$ & $78 \%$ \\
\hline Age 45-59 yrs & $78 \%$ & $68 \%$ & $53 \%$ \\
\hline Age $\geq 60$ yrs & $67 \%$ & $54 \%$ & $18 \%$ \\
\hline GR grade 1 & $84 \%$ & $76 \%$ & $76 \%$ \\
\hline GR grade 2 & $60 \%$ & $48 \%$ & $31 \%$ \\
\hline Tumor vol $<1.2 \mathrm{~cm}^{3}$ & $83 \%$ & $73 \%$ & $56 \%$ \\
\hline Tumor vol $\geq 1.2 \mathrm{~cm}^{3}$ & $60 \%$ & $48 \%$ & $31 \%$ \\
\hline
\end{tabular}

$\mathrm{HPR}=$ hearing preservation rate.

CORRESPONDING ARTICLE See pp 1235-1241. INCLUDE WHEN CITING

Published online October 18, 2019; DOI: 10.3171/2019.9.JNS182765a.

CAANS 2020, except where prohibited by US copyright law

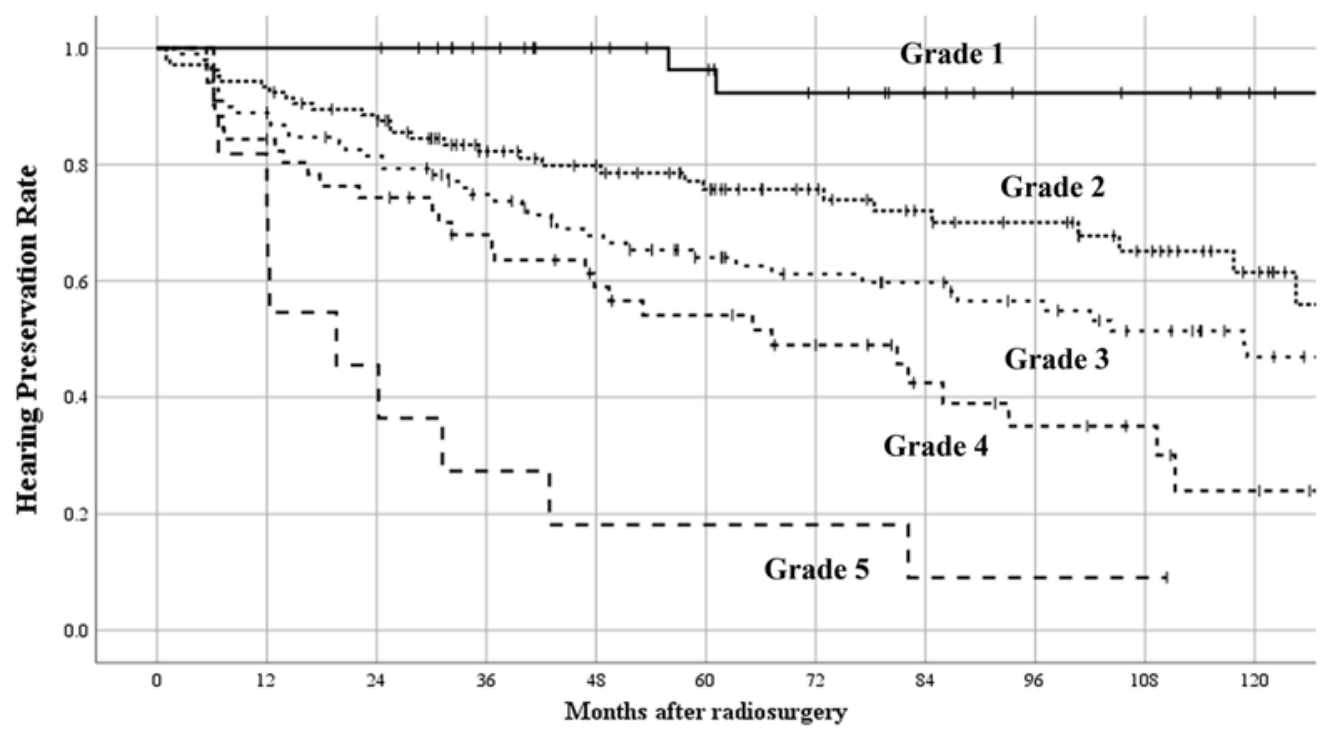

$\begin{array}{lccccc} & \text { No. at Risk } & 3 \text { year } & 5 \text { year } & 10 \text { year } \\ \text { PHPS grade I } & 41 & 35 & 26 & 10 \\ \text { PHPS grade II } & 105 & 71 & 54 & 16 \\ \text { PHPS grade III } & 99 & 65 & 48 & 21 \\ \text { PHPS grade IV } & 51 & 31 & 22 & 4 \\ \text { PHPS grade V } & 11 & 3 & 2 & 0\end{array}$

FIG. 3. Kaplan-Meier plot presenting serviceable hearing preservation rates based on the 5 scores generated from the PHPS system. 